\title{
Comparison of Visual Evoked Potential in Thalassemia Patients Receiving Iron Chelation Therapy
}

\author{
Mridul Yadav' ${ }^{1}$, Shelja Deswal ${ }^{2}$, Beena ${ }^{3}$ \\ ${ }^{1}$ Associate Professor, ${ }^{2}$ Assistant Professor, ${ }^{3}$ Professor, \\ Department of Physiology Pt. BDS PGIMS Rohtak (Haryana)
}

Corresponding Author: Mridul Yadav

\begin{abstract}
Patients of thalassemia require iron chelation therapy for the treatment of iron overload in the form of desferrioxamine (DFO), combination of DFO and deferiprone and oral deferiprone only. One of the side effects of DFO is ocular toxicity. Present study was conducted to elicit the subclinical effects of DFO on visual pathways by doing Visual Evoked Potential (VEP). Forty five patients of thalassemia major were divided into three groups (I, II \&III) based on their iron chelation therapy as desferrioxamine, combination of desferrioxamine \& deferiprone and only deferiprone respectively. VEP was recorded in each group and comparison was done. In VEP P100 was significantly prolonged in the group of thalassemia patients receiving DFO and combination of DFO and deferiprone suggesting vulnerability to ocular toxicity of DFO. We can suggest that in patients receiving chronic DFO therapy, VEPs may be considered to monitor the toxic effects of DFO on visual system.
\end{abstract}

Keywords: Thalassemia, iron chelation, visual evoked potential.

\section{INTRODUCTION}

Thalassemias are heterogenous group of heritable hypochromic anemia of varying degree of severity. Patients of homozygous beta thalassemia die of anemias in infancy unless they are treated with transfusion therapy. Through regular blood transfusions, life expectancy of beta thalassemia patients has improved [1] but new clinical problems have emerged with prolonged survival. Iron overload is a major cause of mortality in patients with homozygous beta thalassemia receiving multiple blood transfusions. The solution for this problem is use of iron chelating agents such as desferrioxamine and deferiprone to prevent accumulation of iron in the body tissues. ${ }^{[2]}$ DFO is administered by parenteral route and Deferiprone is an orally active iron chelator and is suitable for patients who are not able to take DFO due to poor compliance or cost of treatment. ${ }^{[3]} \mathrm{A}$ combination of both drugs is also given to the patients and has been shown to produce additive and synergistic effects. ${ }^{[4]}$

Desferrioxamine has been known to exert significant side effects including sensorimotor neuropathy, renal toxicity, growth retardation etc. Some of the toxic effects are also reported as visual abnormalities i.e. decreased visual acuity, loss of peripheral visual fields, abnormal colour vision, defective dark adaptation, thinning of retinal vessels [5] retinal stippling, ${ }^{[6]}$ abnormal visual evoked potentials and optic neuropathy. ${ }^{\text {[7] }}$

In view of this information our aim was to compare the subclinical involvement of visual system by performing Visual Evoked Potential (VEP) in thalassemia patients receiving different modalities of iron chelation therapy. 


\section{MATERIALS AND METHODS}

The present study was conducted in 45 patients of thalassemia receiving iron chelation therapy. All the patients of thalassemia were more than 5 years of age clinically diagnosed and confirmed by $\mathrm{Hb}$ Electrophoresis attending the Thalassemia Day Care centre. Patients with history of neurological disease, intake of drugs with known ocular neurotoxicity, patients of diabetes mellitus were excluded from the study. The patients were asymptomatic for abnormalities of vision The patients receiving iron chelation therapy for more than 6 months were enrolled in the study. They were divided into three groups of 15 patients each. The first group (Group I) included patients of thalassemia receiving DFO therapy (Injection Desferrioxamine). The second group (Group II) received DFO and Deferiprone on every alternate day. The third group (Group III) included patients receiving Deferiprone alone (oral chelating agent).

Visual evoked Potentials recording was done by using RMS EMG EP MK2 machine. The procedure was explained to the patients and they were seated comfortably in a dark room at a distance of one meter from the recording monitor. Equipment set up for VEP was done as recommended by International federation of Clinical Neurophysiology (IFCN) Committee. ${ }^{\left[{ }^{[8]}\right.}$ Electrodes were placed on the scalp, $\mathrm{O} 1-\mathrm{Fz}$ or $\mathrm{O} 2-\mathrm{Fz}$ montages with reference point at $\mathrm{Fz}$. One eye was tested at a time and the other eye was occluded with a patch. The patient was asked to fix the gaze at a small square at the centre. On VEP monitor visual stimulus in the form of a black and white checker board was generated. The check size was $8 \times 8 \mathrm{~mm}$ subtending an angle of 32 degrees at one meter. The checks were made to reverse at a rate of $1 \mathrm{~Hz}$ and recording of 256 responses was averaged with low and high frequency filters of $2-100 \mathrm{~Hz}$. The latency of $\mathrm{P}_{100}$ was recorded and amplitude $\mathrm{P}_{100}$ from negative wave $\mathrm{N}_{70}$ was measured.

The results were expressed as mean \pm SD of 15 patients in each group. Data was analysed using SPSS version 20.0. The groups were compared using unpaired test and $\mathrm{p}<0.05$ was considered as statistically significant.

\section{RESULTS}

Table 1: Comparison of P100 latencies and amplitudes in Right eye of thalassemia patients

\begin{tabular}{|l|c|c|c|}
\hline \multicolumn{1}{|c|}{ VEP } & Group I (n=15) On DFO & Group II (n-15) On DFO and deferiprone & Group III (n=15) Ondeferiprone \\
\hline P100 Latency $(\mathrm{ms})$ & $119.5 \pm 11.48^{* *}$ & $111.3 \pm 5.98$ & $107.7 \pm 7.62$ \\
\hline P100 Amplitude $(\mu \mathrm{V})$ & $5.01 \pm 0.68 \dagger$ & $5.42 \pm 1.48$ & $6.03 \pm 1.10$ \\
\hline
\end{tabular}

Table 2: Comparison of P100 latencies and amplitudes in Left eye of thalassemia patients

\begin{tabular}{|c|c|c|c|}
\hline VEP & Group I $(n=15)$ On DFO & Group II (n-15) On DFO and deferiprone & Group III (n=15) On deferiprone \\
\hline P100 Latency (ms) & $118.93 \pm 10.9 * \#$ & $110.26 \pm 7.95 \dagger$ & $103.13 \pm 6.68$ \\
\hline P100 Amplitude $(\mu \mathrm{V})$ & $5.08 \pm 0.69 *$ & $5.2 \pm 1.2$ & $5.8 \pm 0.93$ \\
\hline
\end{tabular}

\section{P100 Latency}

In group I mean latency of P100 (119.5 \pm 11.48$)$ was significantly increased $(\mathrm{p}<0.05)$ as compared to group II (111.3 \pm 5.98$)$ and highly significant increase $(p<0.001)$ was observed when compared with group III in both the eyes. On comparing group II with group III mean latency of $\mathrm{P}$ wave was significantly increased $(\mathrm{p}<0.05)$ in left eye but no statistically significant increase in latency was seen in right eye.

\section{P100 amplitude}

The mean amplitude of P100 was significantly reduced $(p<0.05)$ in both the eyes in group I as compared to group III. 


\section{DISCUSSION}

Desferrioxamine was introduced as iron chelator since 1960s to decrease iron overload by increasing the excretion of iron. Desferrioxamine is a member of the hydroxamic acid class of iron chelators which is produced by microbe Streptomyces pilosis. ${ }^{[9]}$ DFO in vitro enters a variety of cells where it binds iron in the labile intracellular pool which is in equilibrium with the storage pool. The DFO- iron complex ferrioxamine exits the cells and is excreted through bile and ferrioxamine formed extracellularly is excreted in urine. ${ }^{[10]}$

Visual evoked potential is an important electrophysiological test to investigate subclinical optic nerve disease. The pattern reversal VEP consists of a prominent positive component at approx. $100 \mathrm{~ms}$ (P100) preceded and followed by negative components N70 and N155. Analysis of the record of VEP is based on the time (latency) and amplitude of P100. ${ }^{[11]}$

In our study abnormalities in VEP was seen as significantly increased latency of P100 in the group I receiving DFO as compared to patients receiving combination of DFO and deferiprone (group II) and oral deferiprone (group III) in both the eyes. Left eye of the patients on combination therapy also had statistically significant increase in latency as compared to those on oral deferiprone.

Our findings corroborate with the findings by Triantfyllou et al who found bilateral increase in latencies of P100 in $32.5 \%$ patients of thalassemia on desferrioxamine therapy and Wong et al who observed that $6 \%$ of thalassemia patients had increased P100 latency in VEP. ${ }^{[12,13]}$ Zafeiriou et al also found that abnormal VEP recordings in thalassemia patients were mainly attributed to DFO neurotoxicity. ${ }^{[14]}$

We also observed significant decrease in the amplitude of P100 in both the eyes in patients on DFO therapy on comparison with patients on oral deferiprone. Similar findings were reported by Freedman et al and Taylor et al where latencies were increased and amplitude of P100 was decreased with abnormal waveforms. ${ }^{[15,16]}$ In contrast to our study, Gelmic C et al observed P100 amplitude significantly greater in thalassemia patients than in controls. ${ }^{[17]}$

Prolongation of VEPs in patients asymptomatic for ocular abnormalities is an indication of subclinical visual pathology beyond retina. ${ }^{[12]}$. DFO has been known to cause retinopathy and optic neuritis in patients receiving this iron chelating agent as therapeutic drug in various diseases. ${ }^{[7]}$ Various mechanisms have been attributed to ocular toxicity mediated by DFO. In an experimental study done in 2010 porcine retinal pigment epithelial (RPE) cells were stimulated with DFO and it was found that DFO induces significant cell death in RPE cells accompanied by phosphorylation of p38 and Erk. ${ }^{[18]}$ DFO, apart from producing consistent increase in iron excretion, also causes increased elimination of zinc and copper. ${ }^{[19]}$ Copper is found in high concentration within RPE, ${ }^{[20]}$ a site which is affected by DFO.DFO induced copper translocation may interrupt with monoaminergic neurotransmission in retina. Synthesis of potential antioxidant neuromelanin may be impaired by reduction of the activity of tyrosinase - copper containing protein, [21] Zinc deficiency enhances lipid peroxidation and impairs the metabolism of amino acids, nucleic acids and proteins. ${ }^{\text {[22] }}$

It has been also reported that DFO toxicity is dose related and also related to the longer mean duration of DFO therapy. Studies have shown that when patients remained off DFO for some months or after a suitable dosage modification was done, tests showed improvement in their VEPs. $[15,16]$

\section{CONCLUSION}

Visual evoked potential studies may be done in patients of thalassemia receiving desferrioxamine therapy either alone or in combination with deferiprone to detect 
subclinical involvement of visual pathway so that appropriate measures can be taken with regard to adjustment of the dose of DFO in these patients.

\section{Acknowledgement: None}

\section{Conflict of Interest: None}

\section{Source of Funding: None}

Ethical Approval: Approved

\section{REFERENCES}

1. Borgna-Pignatti C, Rugolotto S, De Stefano $P$ et al. Survival and complications in thalassemia. Haematologica, 2004;89: 1187-93.

2. Brittenham GM, Griffith PM, Nienhuis AW: Efficacy of desferrioxamine in preventing complications of iron overload in patients with thalassemia major. $\mathrm{N}$ Eng J Med 1994; 331:567-73.

3. Neufeld EJ. Oral chelators deferasirox and deferiprone for transfusional iron overload in thalassemia major: new data, new questions. Blood; 2006(107):3436-41.

4. Galanello R, Agus A, Campus S et al. Combined iron chelation therapy. Ann N Y Acad Sci. 2010 Aug; 1202:79-86.

5. Giardiana PJ, Grady RW. Chelation therapy in $\beta$ thalassemia: an optimistic update. Semin Hematol 2001; 38: 360-6.

6. Mehta AM, Engstorm RE, Kreiger AE. Desferrioxamine associated retinopathy after subcutaneous injection. Am J Ophthalmol. 1994; 118(2):260-1.

7. Orton RB, Veber LL, Sulh HMB. Ocular and auditory toxicity of long-term, highdose subcutaneous deferoxamine therapy. Can J Ophthalmol 1985; 20:153-6.

8. Celesia GG, Bodis-Wollner I, Chatrian $\mathrm{GE}$ et al. Recommended standards for electroretinograms and visual evoked potentials. Report of an IFCN Committee. Electroencephalogr Clin Neurophysiol 1993;87:421-36.

9. Joseph H, Graziano, Cerami A. Chelation therapy for the treatment of thalassemia. Semin Hematol 1977; 14(1):127-34.

10. Hershko C, Rachmilewitz EA. Mechanism of desferrioxamine induced iron excretion in thalassemia. Br. J Haematol. 1979;42; 125-32.

11. Holder GE. Electrophysiological assessment of optic nerve disease. Eye (Lond). 2004 Nov;18(11):1133-43. doi: 10.1038/sj.eye.6701573. PMID: 15534599.

12. Triantafyllou N, Fisfis M, Sideris G et al . Neurophysiological and neurootological study of homozygous $\beta$ thalassemia under long term DFO treatment. Acta NeurolScand 1991; 83:306-8.

13. Wong V, Li A, Lee A.C.W. Neurophysiologic Study of $\beta$-Thalassemia Patients.J Child Neurol. 1993; 8: 330-5.

14. Zafeiriou DI, Economou M, AthanassiouMetaxa M. Neurological complications in beta-thalassemia. Brain Dev;2006:28:47781.

15. Freedman $\mathrm{MH}$, Bondan $\mathrm{M}$, Taylor $\mathrm{M}$ et al. Neurotoxicity associated with DFO therapy. Toxicology 1998; 49: 283-90

16. Taylor MJ, Kenan MK, Gallant $\mathrm{T}$ et al. Subclinical VEP abnormalities in patients on chronic desferrioxamine therapy: longitudinal studies. Electroencephalogr Clin Neurophysiol. 1987;68(2):81-7.

17. Gelmi C, Borgna-Pignatti C, Franchin S et al. Electroretinographic and visual-evoked potential abnormalities in patients with beta-thalassemia major. Ophthalmologica. 1988;196:29-34.

18. Kletnar A, Koinzer S, Waetzig $\mathrm{V}$ et al. Deferoxamine mesylate is toxic for retinal pigment epithelium cells in vitro, and its toxicity is mediated by p38. CutonOculToxicol. 2010;29(2): 12-9.

19. Zaino EC. Desferrioxamine and trace metal excretion in chelation therapy in chronic iron overload. In Zaino EC, Roberts RH eds. Chelation and chronic iron overload. NewYork: CIBAMedical Horizons Symposium 1977.95-101.

20. Bowness JM, Morton RA, Shakir MH. Distribution of copper and zinc in mammalian eyes. Occurrence of metals in melanin fractions from eye tissues. Biochem J; 1952: 51:521

21. Pall H, Blake DR, Winyard P et al. Ocular toxicity of desferrioxamine- an example of copper promoted auto-oxidative 
Mridul Yadav et.al. Comparison of visual evoked potential in thalassemia patients receiving iron chelation therapy

damage? British Journal of How to cite this article: Yadav M, Deswal S, Ophthalmology. 1989;73:42-7. Beena. Comparison of visual evoked potential in

22. Virgiliis SD, Congia M, Turco MP et al. Depletion of trace elements and acute ocular toxicity induced by desferrioxamine in patient with thalassemia patients receiving iron chelation therapy. International Journal of Research and thalassemia. Arch Dis Child. 1988; Review. 2021; 8(12): 125-129. DOI: https://doi.org/10.52403/ijrr.20211217 63:250-5. 